\title{
Investigation of Alumina Nano Fluid Thermal Conductivity
}

\author{
Akram W.Ezzat, PhD \\ Department of Mechanical \\ Engineering \\ University of Baghdad
}

\author{
Ikhlas M.Hasan \\ Department of Mechanical \\ Engineering \\ University of Baghdad
}

\begin{abstract}
The paper studies experimentally the enhancement in thermal conductivity of Nano fluid $\gamma-\mathrm{Al}_{2} \mathrm{O}_{3} /$ distilled water $(10 \mathrm{~nm}$ particle size) at four different volume fractions $(0.13,0.24,1$ and $1.7 \%$ ). The Alumina powder posses the following specifications: spherical, 99\% purity, white appearance, 3700 bulk density, $160 \mathrm{~m}^{2} / \mathrm{g}$ specific surface area, $880 \mathrm{~J} / \mathrm{kg} . \mathrm{K}$ specific heat, $46 \mathrm{~W} / \mathrm{m} . \mathrm{K}$ thermal conductivity. The tests performed at average temperatures $\left(37.9^{\circ} \mathrm{C}\right.$ and $\left.44.23^{\circ} \mathrm{C}\right)$. The effect of both temperature and Nano fluid volume fraction on its thermal conductivity is investigated. The fluid is allowed to flow in annulus cooling channel subjected to constant heat fluxes $\left(20693 \mathrm{~W} / \mathrm{m}^{2}\right.$ and $\left.27752 \mathrm{~W} / \mathrm{m}^{2}\right)$ which corresponds to Nano fluid temperature, $\mathrm{T}_{\mathrm{nf}}\left(37.9^{\mathrm{O}} \mathrm{C}\right.$ and $44.23^{\circ} \mathrm{C}$ ). Thermal conductivity of the fluid is measured using Decagon KD2-senser. The experimental results showed an enhancement in the ratio of Nano fluid thermal conductivity to distilled water thermal conductivity, $\frac{\mathrm{k}_{\mathrm{nf}}}{\mathrm{k}_{\mathrm{bf}}}$ of about (0.34.5\%). The experimental results are then compared with those related to other results obtained using correlations elaborated from previous works.
\end{abstract}

Keywords: Nano fluid, enhancement, preparing, suspension.

\section{INTRODUCTION}

Nano fluid means containing the suspended crystalline solid particles in fluid which display significantly enhanced thermal conductivity as crystalline solid have thermal conductivity of typical 1-3 order of magnitude larger than those of traditional heat transfer fluid. Various experimental facts observed in previous works based in the extensions and modifications to Maxwell's equation [1873], which take the thermal conductivity of Nano particle and base fluid as well as the volume fraction, particle shape, surface area, the distribution of the dispersed particles and thermal conductivity of Nano layer effects into account. In this paper the experimental and the theoretical studies by, Das et. al 2003[1] investigated the increases thermal conductivity with temperature for $\left(\mathrm{Al}_{2} \mathrm{O}_{3}\right.$ and $\mathrm{CuO})(38.4 \mathrm{~nm}, 28.6 \mathrm{~nm})$ respectively with different concentrations (1-4\%) using oscillation technique to measure thermal conductivity and thermal diffusivity. The results indicated an increase in thermal characteristic of Nano fluid with temperature at high density load than at room temperature. Yu and Choi 2003[2] showed the effects of Nano layer thickness, $h$ to original particle radius, $r$ for $\mathrm{Cu} / \mathrm{EG}$ $(<0.1 \mathrm{~nm})$ at $(1 \% \mathrm{Vol}$.) .They observed an increase in thermal conductivity for up to 8-fold compared with Maxwell model.
Yu and Choi 2004 [3] included the particle -liquid interfacial layer for the predication of thermal conductivity of three phase suspension particle for carbon Nano tube /oil. They predicated a new model depended on the empirical shape factor and found the enhancement in thermal conductivity because of interfacial layer. Hong and Yang 2005[4] measured the thermal conductivity of $(\mathrm{Fe})$ at $(10 \mathrm{~nm})$ with volume fraction (up to $0.55 \%$ ) by transient hot wire and they showed that the enhancement in thermal conductivity up to $18 \%$ as the sonication time up to $50 \mathrm{~min}$ by ultrasonic device (Jeiotech.ULH-700S).Putnam et.al 2006[5]measured thermal diffusivity of $\mathrm{Au}(4 \mathrm{~nm}$ and $2 \mathrm{~nm})$ at $\phi<1 \%$ concentration volume by micro scale beam deflection technique .They did not observe anomalous enhancement of the thermal conductivity. The largest increase in the thermal conductivity is $1.3 \pm 0.8 \%$ for $4 \mathrm{~nm}$ diameter $\mathrm{Au}$ particle suspension .Zhu et.al 2009 [6] studied the stability and thermal conductivity $\mathrm{Al}_{2} \mathrm{O}_{3}$ of $(15-50 \mathrm{~nm})$ with weigh fraction $(0.02-0.15 \%)$ under different $\mathrm{PH}$ values and add (sodium dodecylbenzenesulfonate SDBS) as dispersant. The hot disk thermal constants analyzer is used to measure thermal conductivity. They also showed the enhancement of the thermal conductivity with the increase of particle concentration up to $10.1 \%$ at the $0.15 \%$ wt. Minsta et.al 2009 [7] investigated thermal conductivity with temperature range $\left(20^{\circ} \mathrm{C}-40^{\circ} \mathrm{C}\right)$ at several particle volume fraction for $\left(\mathrm{Al}_{2} \mathrm{O}_{3} /\right.$ water $36 \mathrm{~nm}$ and $\left.47 \mathrm{~nm}\right)$ and $(\mathrm{CuO} /$ water $29 \mathrm{~nm})$. They observed that effective thermal conductivity increase with temperature of $15 \%$ for each type. Hezareh and Moraveji 2011[8] studied the new model of effective the thermal conductivity for $\mathrm{Al}_{2} \mathrm{O}_{3}$ /water/EG for (1-5\%) volume fraction. They explained that the new model is function of the thermal conductivity of based fluid, solid particle, shape factor and volume fraction. They also measured the thermal conductivity by transient hot -wire method. Abadi and Zamzamian 2013 [9] studied experimentally the Al/water and $\mathrm{Cu} /$ water $(25 \mathrm{~nm}$ and $35 \mathrm{~nm}$ respectively) with three different concentration $(500,1000,2000 \mathrm{ppm})$. They measured thermal conductivity by KD2.Pro.at wide range of temperature $\left(35^{\circ} \mathrm{C}-45^{\circ} \mathrm{C}\right)$. They showed dramatic increase in thermal conductivity with increase in temperature about $12 \%$ for $\mathrm{Cu} /$ water at $2000 \mathrm{ppm}$ and (11-22\%) for $\mathrm{Al} /$ water at same concentration.

The main object of this study is to investigate new method for thermal conductivity measurement of the Nano fluid to ensure the accuracy and avoid the settling of Nano particles during test and compare the results obtained from recent experimental work with those obtained from other researches. 


\section{EXPERIMENTAL WORK}

\subsection{Preparation of nano fluid.}

To investigate the effect of Nano particles on heat transfer, all the physical properties of $\gamma-\mathrm{Al}_{2} \mathrm{O}_{3}$ shown in supplier (Nanostructured\& Amorphous Materials Ins.U.S.A) are based in the calculations related to experimental work. The Nano fluid is prepared using two step methods. The powder is dispersed in distilled water and the mixture homogenized the using ultrasonic probe and magnetic stirrer. The specifications of both devices are (CPX-750Watt, MSH-20AWisd) respectively. Plate 1 show both devices used for homogenization of Nano fluid. The following steps are implemented to prepare the Nano fluid;

a. The dispersion of particles is conducted first by mixing the required volume $(400 \mathrm{ml})$ of the powder in beaker with distilled water and then using magnetic stirrer. This procedure is repeated for 5 times until the required volume that is used in the test (2 Liter) is homogenized completely.

b. To Estimate the volume fraction of the Nano powder the weight of the Nano powder is measured using electronic weighting apparatus and then the known weight of the powder is dispersed in known mass of water. Then volume fraction of the powder is calculated based on the known percentage of volume fraction, known density of the particle, known density of water by using the Law of mixture;

$$
\text { Volume fraction } \%=\frac{V_{p}}{V_{t}}=\frac{\frac{m_{p}}{\rho_{p}}}{\frac{m_{p}}{\rho_{p}}+\frac{m_{w}}{\rho_{w}}}
$$

c. After preparing the proper mixture the ultrasonic probe is immersed in the mixture to homogenize the Nano particles with the fluid with magnetic stirrer together. The duration of this process is up to 6 hours.

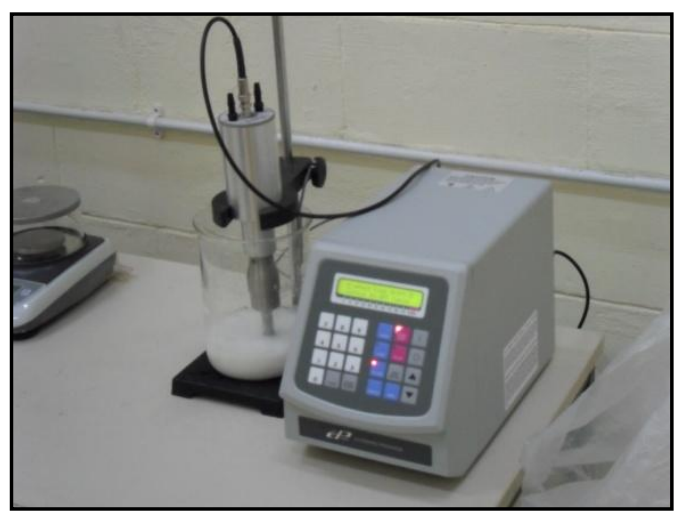

Plate 1: Ultrasonic processor.

\subsection{Measurement of thermal conductivity of nano fluid.}

The thermal conductivity of Nano fluid could be measured with the Decagon KD2.sensor, see plate 2. It is based on the transient hot-wire technique in principle of the measurement. The probe of this KD2 analyzer has $1.3 \mathrm{~mm}$ diameter and $60 \mathrm{~mm}$ and contains both the heating element and thermistor type KS-1 prob.
A two average temperature of Nano fluid in present work are due to flow it in closed loop system which consists of the vertical heated annulus channel which is consisted from isothermal the outer wall and the inner wall is heated by a uniform heat flux $\left(20693 \mathrm{~W} / \mathrm{m}^{2}\right.$ and $\left.27752 \mathrm{~W} / \mathrm{m}^{2}\right)$, flask, pump, and heat exchanger to cool nano fluid to initial condition.

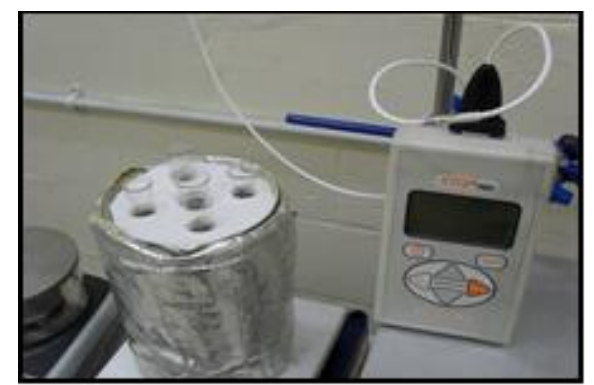

Plate 2:KD2.Pro.device

\subsection{Measurement procedure}

This test method presents a procedure for determining thermal conductivity of Nano fluid by using the thermal needle probe apparatus that should be calibrated before its use. The calibration is performed by comparing the experimental determination of thermal conductivity of distilled water to its known values in text book and literatures. Sample of approximate $55 \mathrm{ml}$ Nano fluid is sealed in a glass test tube, then the multi test tube are fixed together to ensure temperature measurement accuracy see figure 1 . The probe was inserted vertically into a predrilled hole in a sealed test tube. Special care should be taken to ensure that the thermal probe is fully embedded in the sample, once the specimen reached to equilibrium temperature after 5-10 min. At least five readings were considered at each fluid temperature with same time intervals. Settling of the Nano powder should be avoided during the implemented measurement procedure by using magnetic stirrer that is used also as power supplier to system. The beaker should also be insulated by glass wool at $25 \mathrm{~mm}$ thickness to avoid free convection to environment and delay heat loss process.

\subsection{Recycling nano powder}

Based on previous practical experience it is decided to recycle the fluid in a scale laboratory simplest way. Based on the sample test of the Nano fluid after certain operation experiments, it is found that particle size reached $18.35 \mathrm{~nm}$ while it size was $15.88 \mathrm{~nm}$ at first experiment see figures (2-5) and plate 3 .

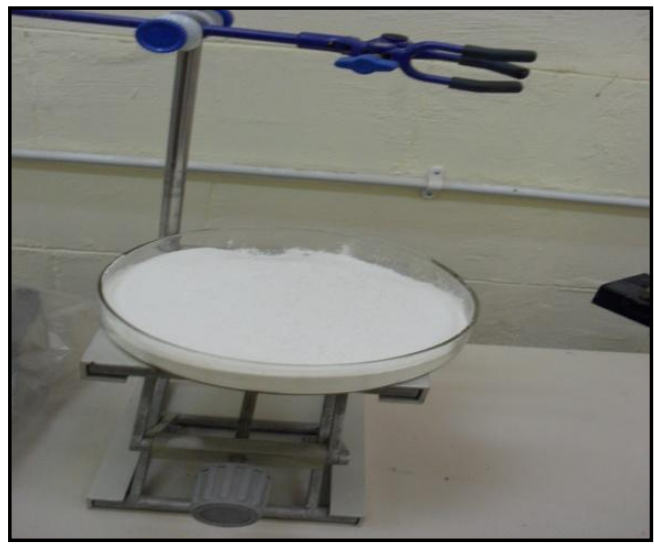

Plate 3: Powder recycled 


\section{RESULTS AND DISSCUSION}

The effect of Nano particles volume fraction on Nano fluid thermal conductivity could be observed on the figures that represents the experimental measurement results. The results represent they fluid thermal conductivity versus the average value of five repeated temperature measurement results at a specific concentration. Figures (6 and 7) show thermal conductivity of $\gamma-\mathrm{Al}_{2} \mathrm{O}_{3}$ Nano fluid versus the Nano particle volume fractions $(0,0.13,0.24,1$, and $1.7 \%)$, which is prepared from $10 \mathrm{~nm}$ powder and measured at $\left(37.9^{\circ} \mathrm{C} \& 44.23\right.$ $\left.{ }^{\circ} \mathrm{C}\right)$ temperatures. The figures illustrate also the data reported by Honorine et. al 2009[7], Hadi and Mostaf 2011[8], and the prediction from the Maxwell model (1881). The previous experimental results related to prediction of thermal conductivity together with the measured values in the recent study increase versus the increase of volume fraction linearly with different slopes. These differences among results are due to various factors such as the particle size, the particle source, the shape of nanoparticle, measurement technique, adding amount of surfactant, different techniques used for particle preparation and the time duration for ultra -sonication process. Comparing recent data with the predicted values of other models based on their correlations, the results showed minimum deviation among them of ( $2.99 \%$ compared with Maxwell correlation), ( $2.84 \%$ compared with Hadi and Mostaf correlation), (1.11\% compared with Honorine et.al) at fluid temperature, $\operatorname{Tnf}$ equals $37.9^{\circ} \mathrm{C}$, while at fluid temperature, $\mathrm{T}_{\mathrm{nf}}$ equals $44.23^{\mathrm{O}} \mathrm{C}$ the deviation was $(2.85 \%)$, $(2.79 \%)$, and $(2.2 \%)$ respectively. The results showed good agreement with (Honorine et.al) correlation at $\mathrm{T}_{\mathrm{nf}}$ equals $37.9^{\circ} \mathrm{C}$. This agreement is based on using the same measurement techniques and procedure at low heat flux at which the effect of aggregation of Nano particle is smaller than that related to high temperature. See Table (1). The experimental data related to fluid temperature effect on thermal conductivity of alumina nano fluid is showed in figure (8). The results cleary show the thermal conductivity increase with increase in temperature between $\left(37.9^{\circ} \mathrm{C}-44.23\right.$ $\left.{ }^{\circ} \mathrm{C}\right)$.

\section{CONCLUSION}

As it is clear from the experimental results, the enhancement in the thermal conductivity $\left(\frac{\mathrm{k}_{\mathrm{nf}}}{\mathrm{k}_{\mathrm{bf}}}\right)$ ratio in comparison with the base fluid (distilled water) increases versus the volume fraction of Nano fluid powder $\left(\gamma-\mathrm{Al}_{2} \mathrm{O}_{3}\right)$. This increase is $(2.8-4.5 \%)$ for the volume fraction $(0.13,0.24,1$ and $1.7 \%)$ at $\mathrm{T}_{\mathrm{nf}}=37.9^{\circ} \mathrm{C}$, while it is $(0.32-3.05 \%)$ at $\mathrm{T}_{\mathrm{nf}}=44 \cdot 2^{\circ} \mathrm{C}$. Also there is an increase in thermal conductivity versus fluid temperature increase which takes the same tendency of distilled water behavior for temperature range $\left(37.4^{\circ} \mathrm{C}-44.23\right.$

${ }^{\circ} \mathrm{C}$ ). The best way to obtain the homogenous Nano fluid is realized by using the magnetic stirrer and ultrasonic probe devices together at same time.

\section{NOMENCLATURE}

I: current

$\mathrm{K}$ : thermal conductivity

$\mathrm{K}_{\mathrm{e}}$ : effective thermal conductivity

$\mathrm{K}_{\mathrm{l}}$ : thermal conductivity of liquid m: mass

$\mathrm{V}$ : voltage

$\mathrm{T}$ : Temperature

\subsection{Greek letter}

$\varphi$ : Volume fraction

$\gamma:$ Crystalline phase

\subsection{Subscript}

bf: based fluid

nf: nano fluid

p: particle nano powder

r: ratio

t: total

w: water

\section{ACKNOWLEDGEMENT}

I would like to show my gratitude to Asst. Prof. Dr. Akram W. Ahmed Ezzat and Dr. Abdul Kareem AL- Sammarraie.

\section{REFFERENCES}

[1] Das, S.K., et.al, [2003],"Temperature Dependence of Thermal Conductivity Enhanced for Nano fluid", Journal of Heat Transfer vol.125, (567-574).

[2] Yu,W. and Choi, S.U.S ., [2003],"The role of interfacial layer in the enhanced thermal conductivity of nano fluids: A renovated Maxwell model", Journal of Nano particle Research5:167-171.

[3] Yu,W. and Choi, S.U.S ., [2004],"The role of interfacial layer in the enhanced thermal conductivity of nano fluids: A renovated Hamilton-Crosser model", Journal of Nano particle Research6:355-361.

[4] Hong, Tae-Keun and Yang, Ho.Soon., [2005],"Study of The Enhanced Thermal Conductivity of Fe Nano fluids", Journal of Applied Physics97, 064311.

[5] Putnam, Shawn A., et .al, [2006],"Thermal Conductivity of Nano particle Suspensions", Journal of Applied Physics", 084308.

[6] Zhu, Dongshang., et.al,[ 2009],"Dispersion Behavior and Thermal Conductivity Characteristics of AL2O3- H2O Nano fluids", Current Applied Physics", 9, (131-139).

[7] Mintsa, Honorine Angue., et.al, [2009],"New Temperature Dependent Thermal Conductivity Data for Water -Based Nano fluids", International Journal of Thermal Science (363-371).

[8] Hezaveh, Hadi., and Moraveji, Mostaf Keshavarz. , [2011],"Modeling Effective Thermal Conductivity Of $\mathrm{AL}_{2} \mathrm{O}_{3}$ Nanoparticle In Water and Ethylene Glycol Based On Shape Factor", International Journal Of Chemical Engineering and Applications, Vol, 2, No.1, Issn: 2010-0221.

[9] Abadi, M.Tajik Jamal and Zamzamian, A.H., [2013],"Thermal Conductivity of $\mathrm{Cu}$ and Al-Water Nano fluids", International Journal of Engineering Vol.26, No.8, (821-828). 
Table 1: Correlations related to previous models used for thermal conductivity investigation

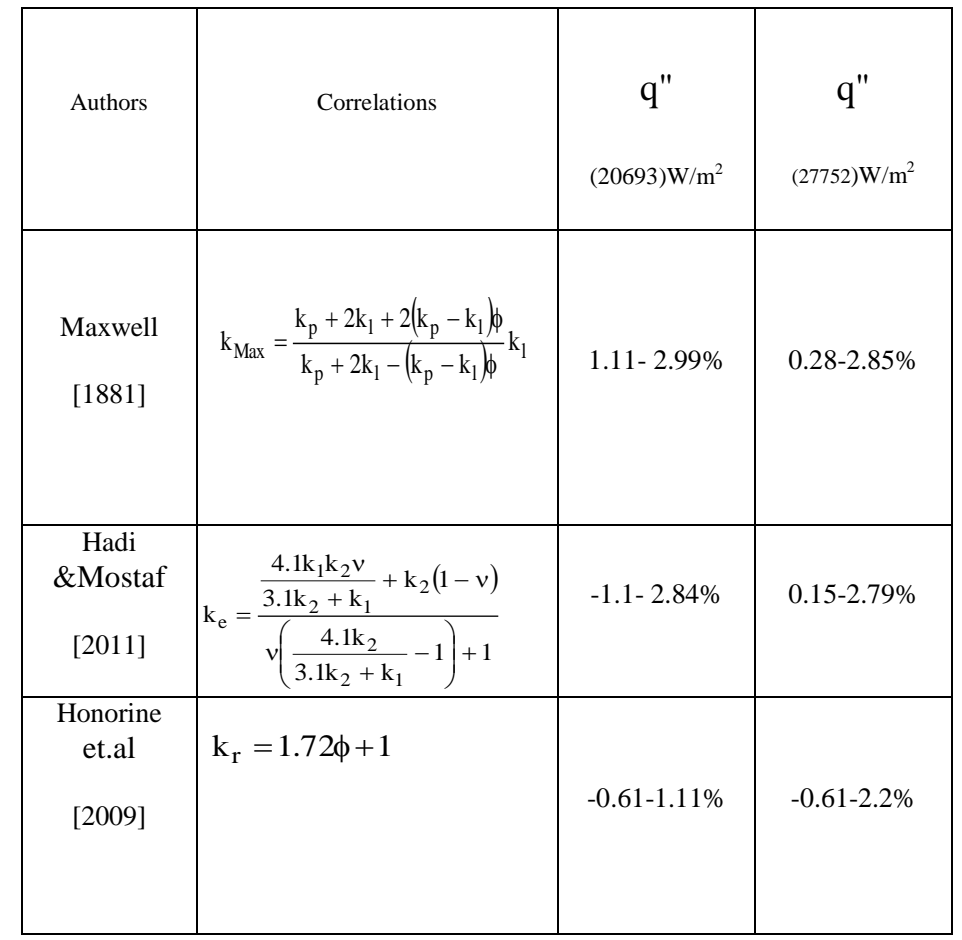

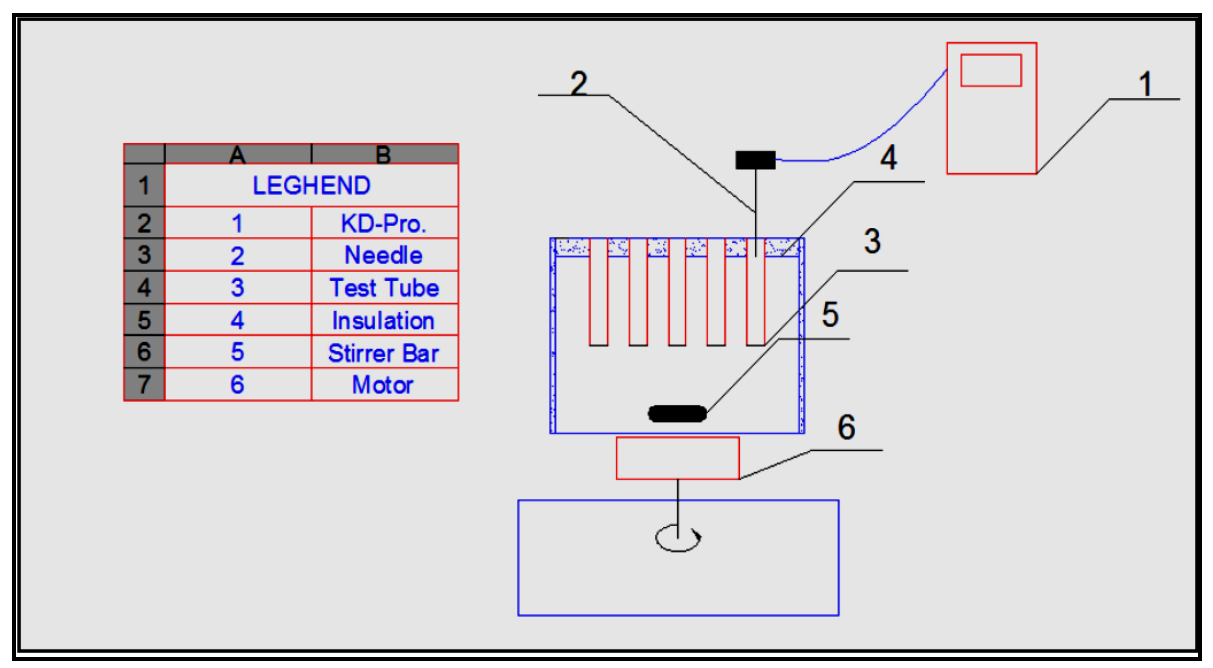

Figure 1: Schematic diagram of thermal conductivity test 


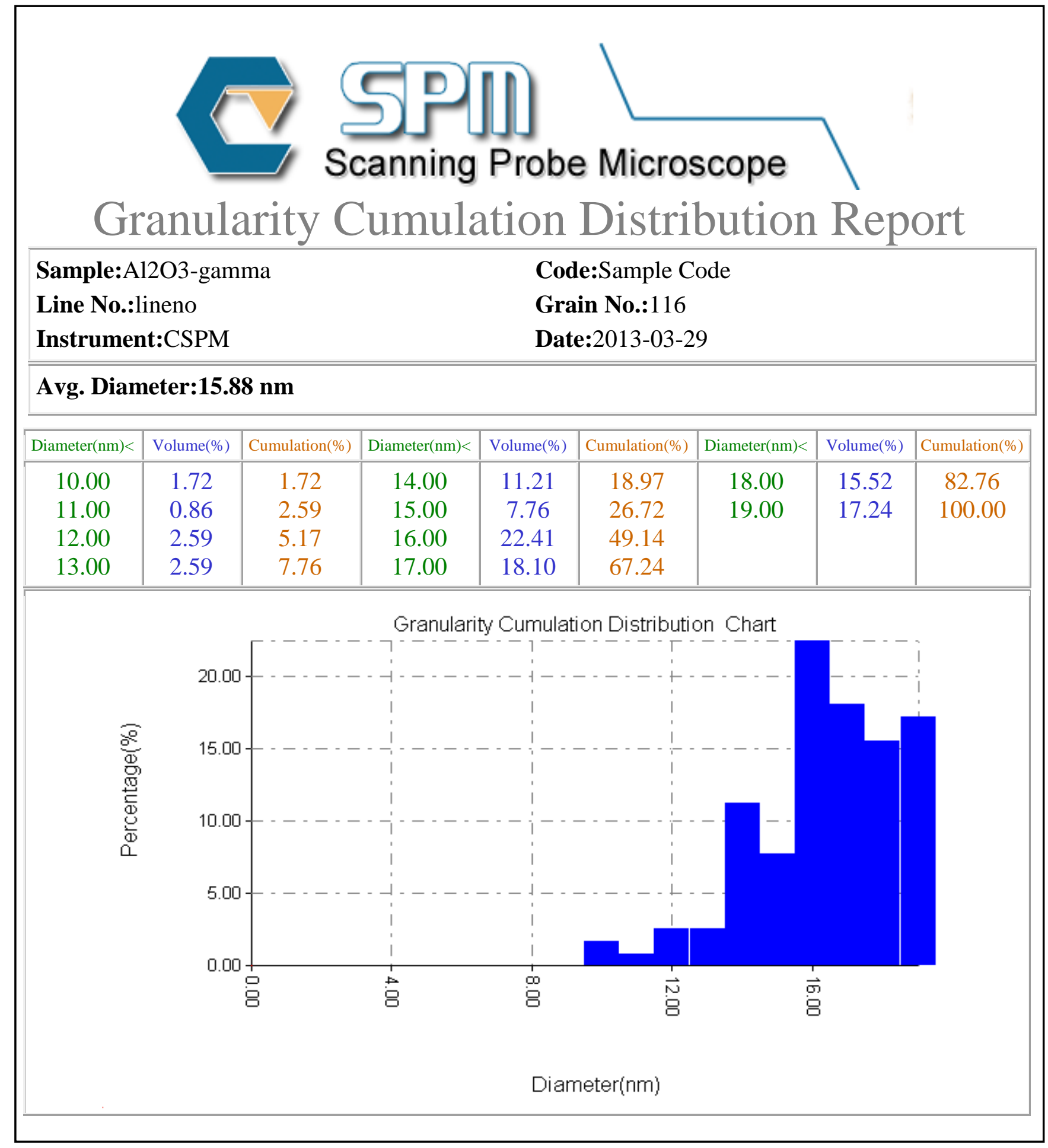

Figure 2: Certificate related to alumina particle size before recycle 


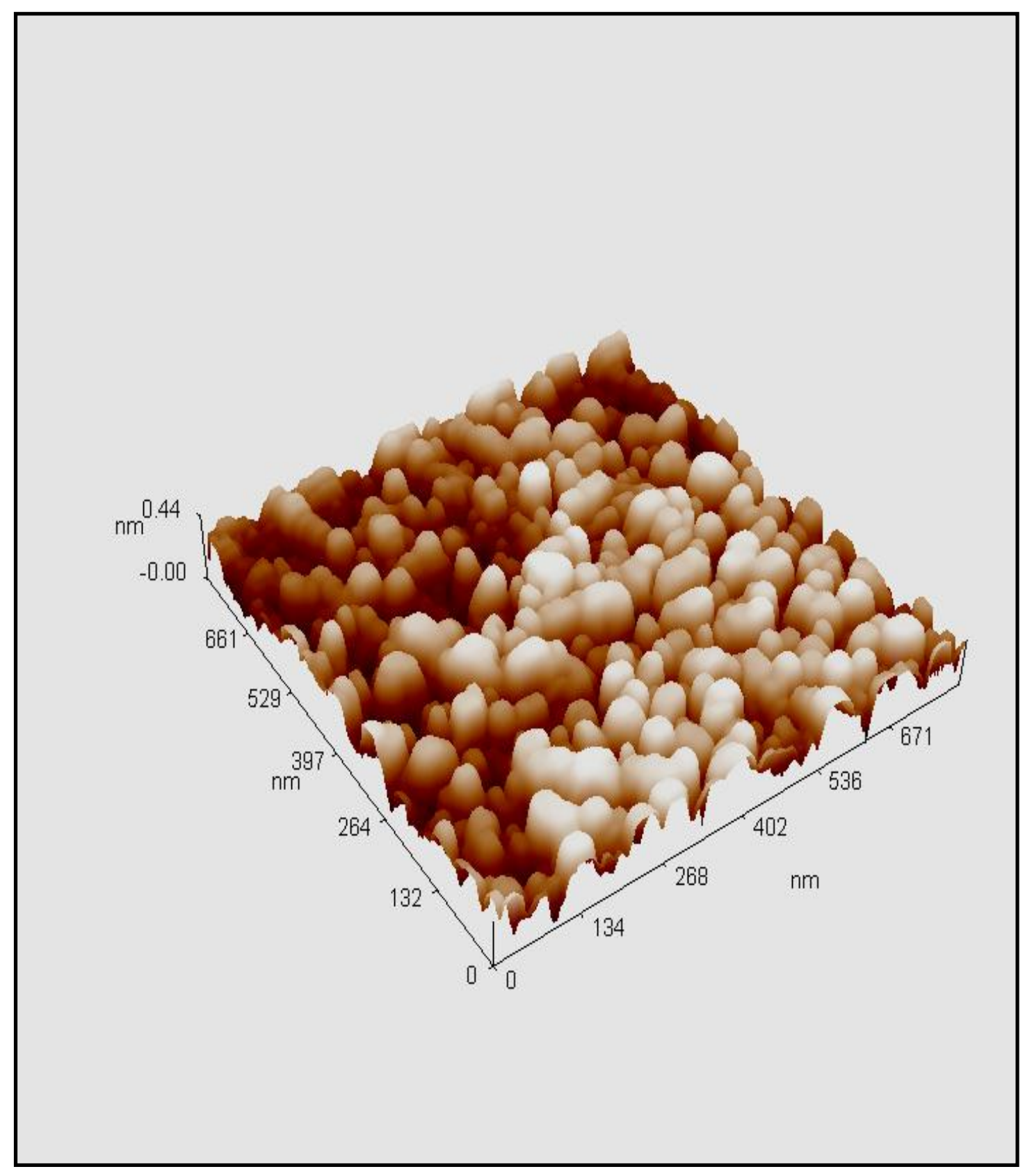

Figure 3: 3D AFM view image of alumina before recycle 


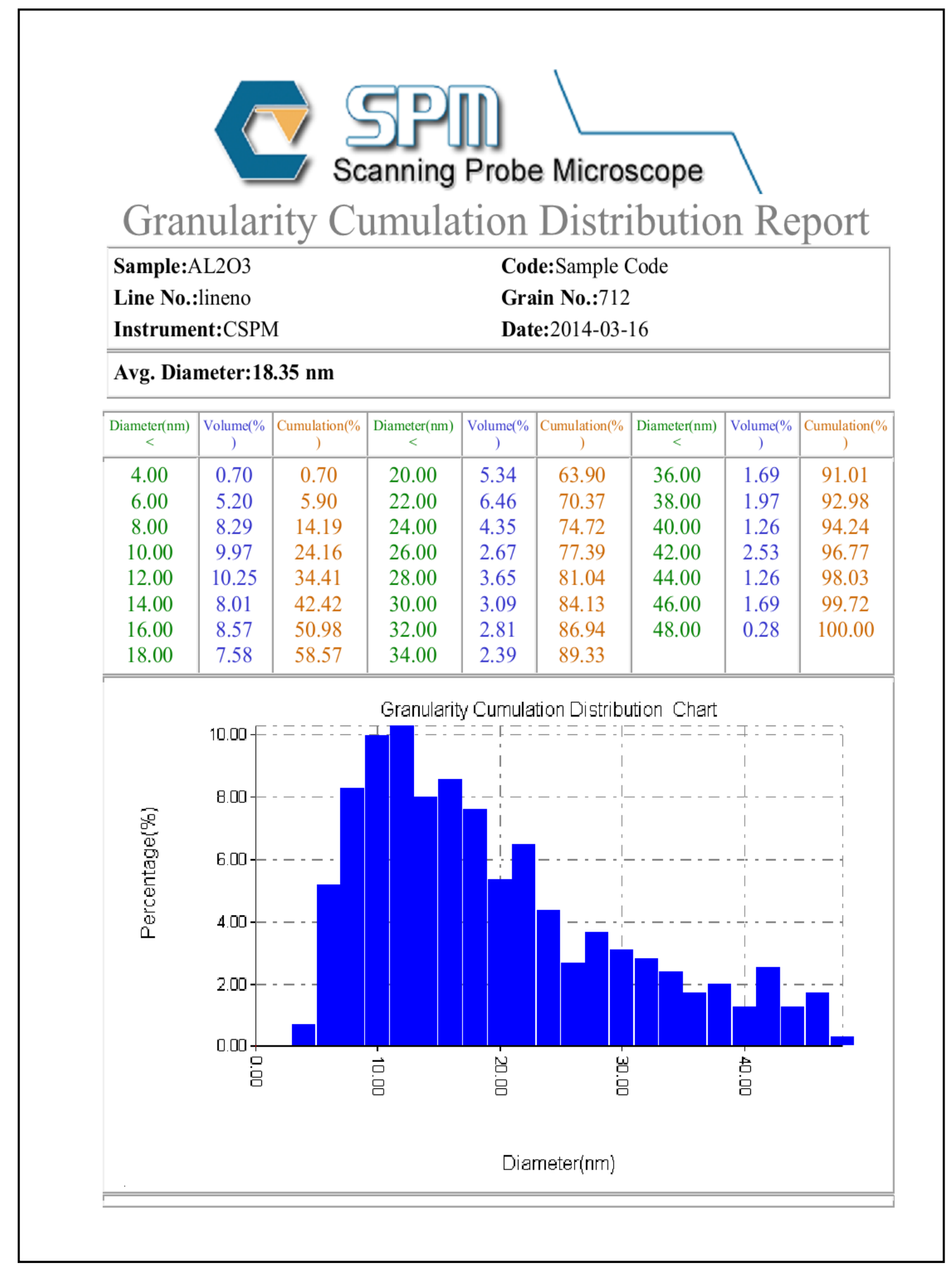

Figure 4: Certificate related to alumina particle size after recycle. 


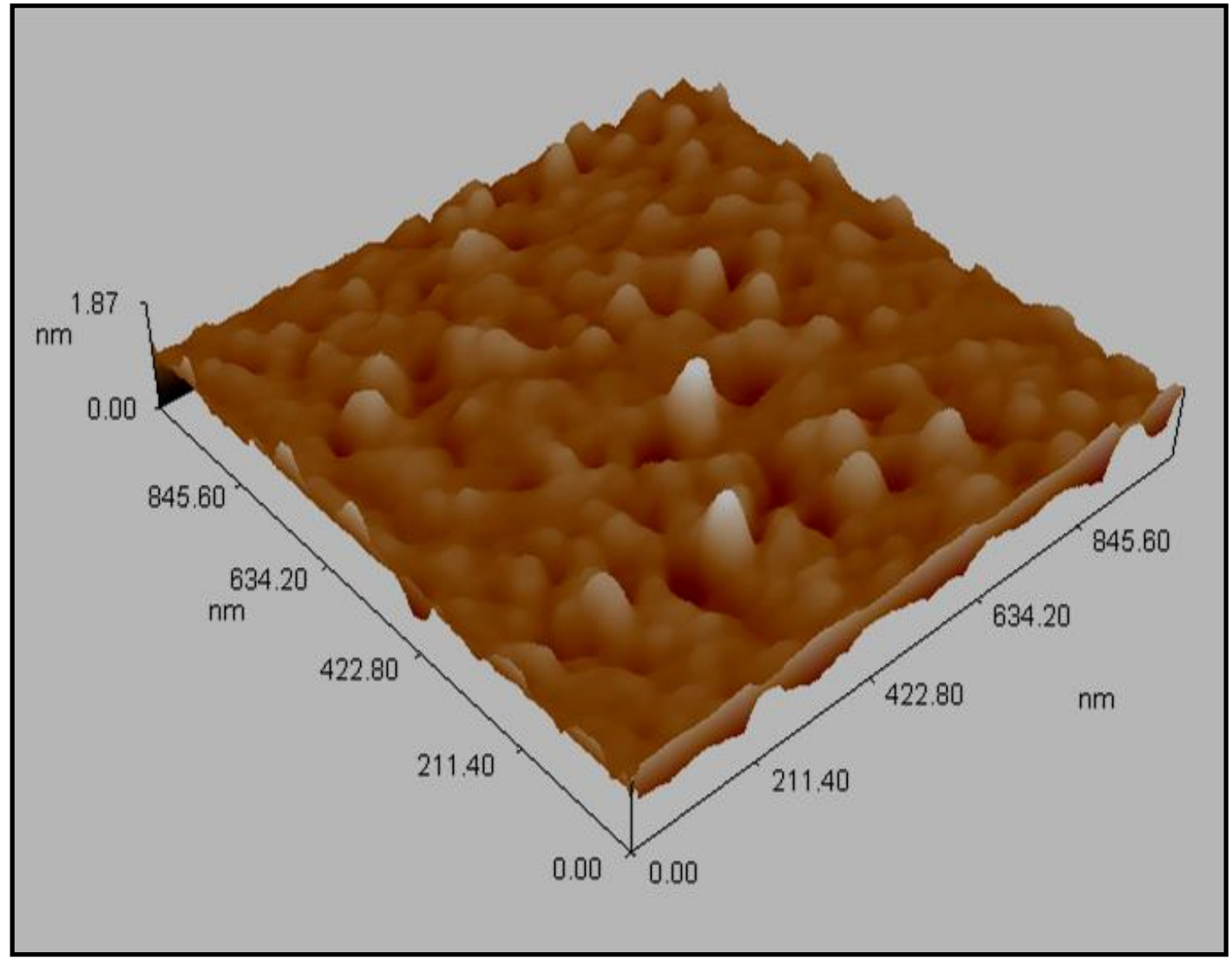

Figure 5: 3D AFM view image alumina after recycle.

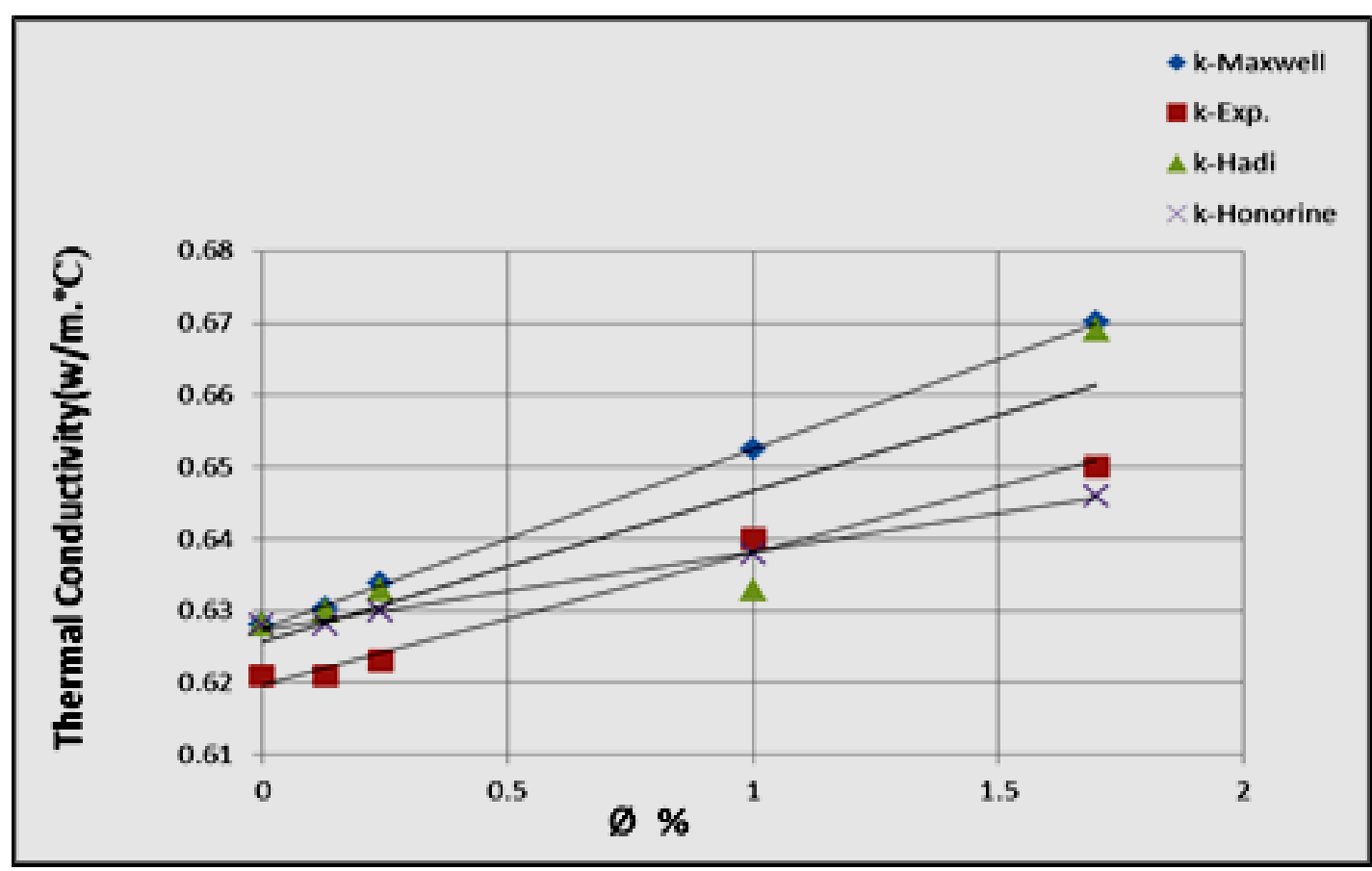

Figure 6: Comparison of $\left(\gamma-\mathrm{Al}_{2} \mathrm{O}_{3}\right)$ nano fluid thermal conductivity obtained from recent experiments with those obtained from previous works at fluid temperature, $\mathrm{Tnf}=37.9^{\circ} \mathrm{C}$ 


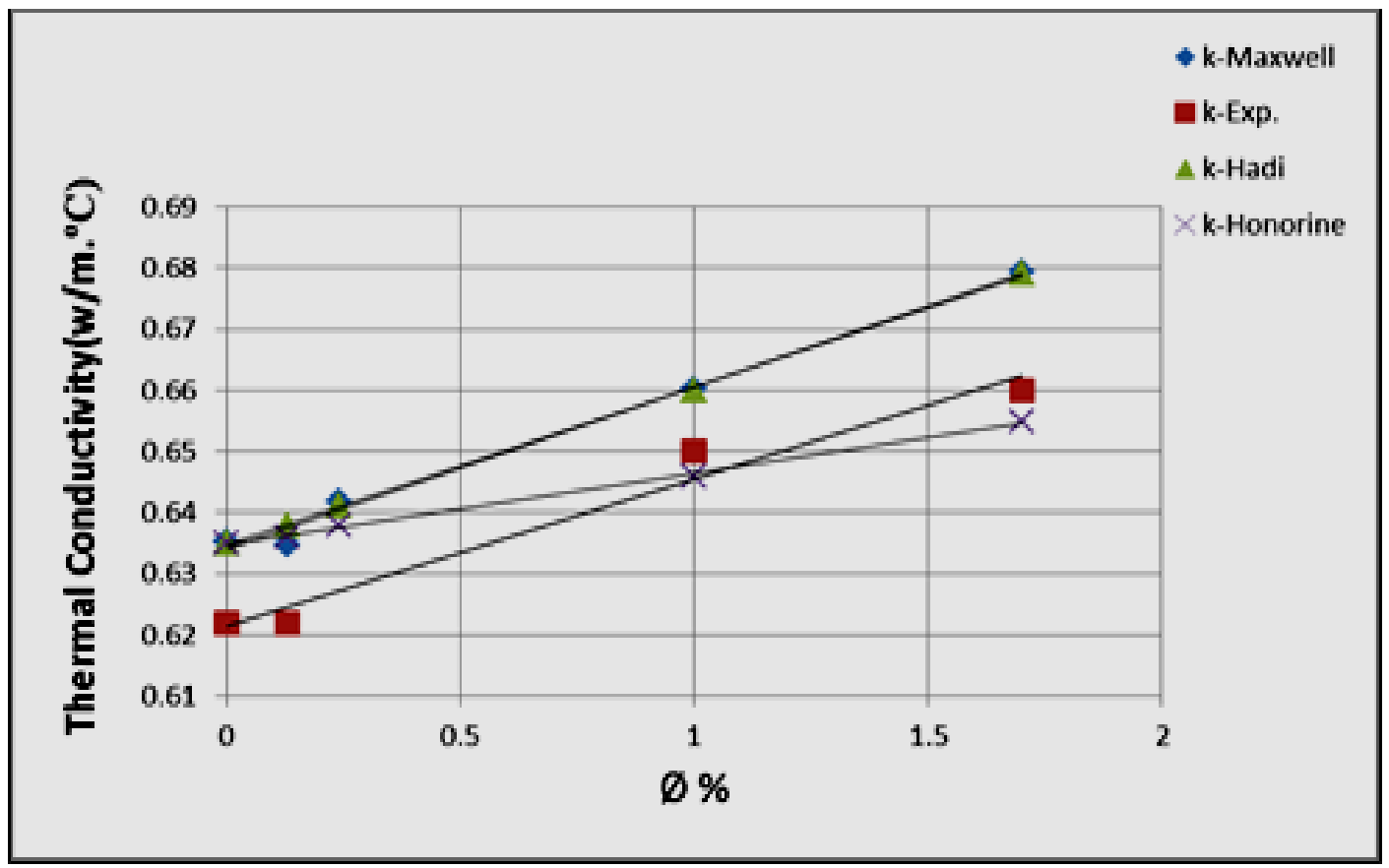

Figure 7: Comparison of $\left(\gamma-\mathrm{Al}_{2} \mathrm{O}_{3}\right)$ nano fluid thermal conductivity obtained from recent experiments with those obtained from previous works at fluid temperature, $\operatorname{Tnf}=44.23^{\circ} \mathrm{C}$

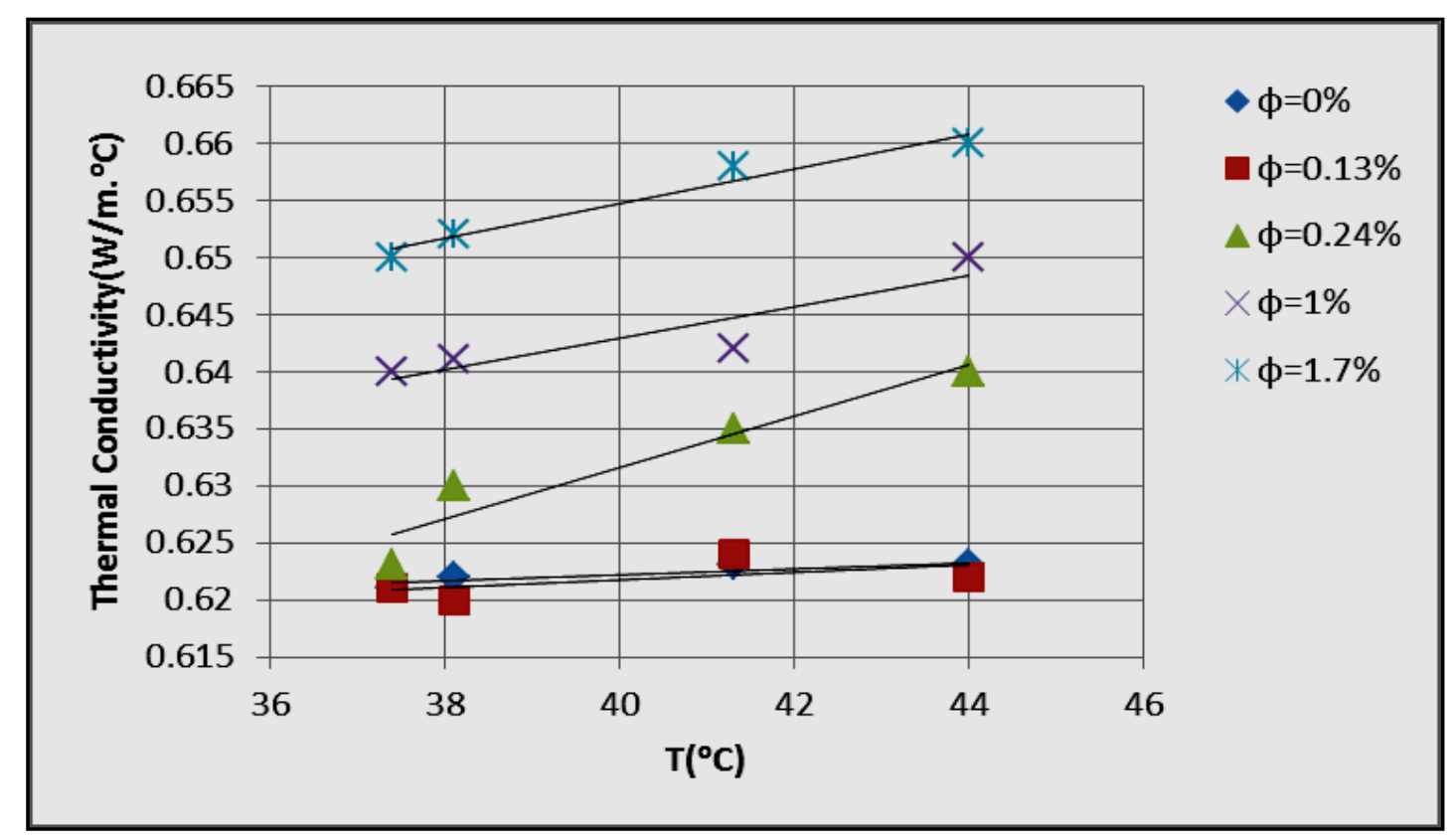

Figure 8: Thermal conductivity of $\left(\gamma-\mathrm{Al}_{2} \mathrm{O}_{3}\right)$ nano fluid versus fluid temperature at different nano particles volume fraction 